\title{
GLOBAL PARADOX OF RACE: SPIRITUAL TRANSCENDENCE
}

\author{
* Dr. Lubna Ahsan, California, United States (lubnaahsan12@gmail.com)
}

\begin{abstract}
This paper is a critical analysis of the poem "Indigo Brown" by Will Cox, a Modern American prolific writer, poet, philosopher, essayist, vociferous activist and humanist. It is an in-depth study to inspire people to get rid of their ego and live through their soul. The poet has introduced the idea of negative capability as he believes that the societal taboos lead to intellectual muddle and insecurity. The poet draws a bridge between the never ending heartaches of the past and connects them beautifully with the present state where he has gathered himself and lifts his head to reconcile with the never changing customs. However, the question of freedom has an everlasting impression at the back of his head and expresses a desire to transcendence to a spiritual realm, traveling beyond time to purify his soul from the unworthy assertions society has labeled him with. His style is direct and rhetoric and he uses significant symbols, imageries and literary devices and also uses authorial intrusion to establish his point of view.
\end{abstract}

KEYWORDS: Indigo-brown, Transcend, Escape, Indoctrination, Soul-searching

The gist of the poem Indigo Brown is that we all are the same as we all have a soul, we are soul living separate lives. We are all born with the same body and the same heart and mind. What makes us different is that we are placed in unique circumstances, are exposed to different backgrounds, different demographics, geographical conditions, and the features that were born with our physical appearance. (Hernandez, \& Blazer, 2006) The only significant physical difference between humans is the pigment of their skin, the physic of their body, their eye color, their hair, etc.; all these are just hypothetical ideas that make us different. It means that we were unknowingly made a part of a particular family, clan, tribe or race. The soul is the sum of our collective consciousness and represents the entire existence of elements. The soul is a source of courage, strength and wisdom. It can't be harmed by people's criticism and external circumstances. The soul is the essence of our true self. It is 
the reality deep down the tags we carry in this world and the social status we live and the labels that seem to be our identity. The soul never changes, it is something we were born with and it remains the same. It is a very powerful and untainted element in us. It connects us with life energy only because it is an embodiment of reality. (Bedrich, 2008)

Once we become part of this world we are segregated and divided geographically, economically, by religion, color, etc. The bottom line is that we are all connected with the same element, and energy. (Sharmila, 2013) We are not from where we belong (our background \& ancestry) but we are from God, we all come from Heaven. The soul has no physical form but this world judges on the basis of appearance.

Racism is a worldwide phenomenon that deals with a variety of aspects of intolerance. The never ending debate on ethnic and cultural miscellany is an established never-ending taboo. Globally it is treated with disapproval and denial. (Brian, 2001), It denotes superiority of one race over the other, which frequently gives rise to discrimination and partiality based on their race or ethnicity. (Judith, 1995) It is the treatment of making differentiation in favor of or against a person connected with a group, or clan which the person belongs to. It is worse than the way people are generally treated". (Cambridge Dictionaries Online. 2013) The fundamentals underlining these racist ideologies usually subdivide people into distinctive groups that are dissimilar based on their social conduct and their instinctive abilities as well as the indication that they can be categorized as inferior or superior. (Introduction to sociology. 2009)

The poem Indigo Brown is a conscious self-echoing encounter. The poet Will Cox does not hold any sort of prejudice against any race, religion or culture. The poem is just an expression of what he has witnessed in the society. The poem is divided into two parts; the initial part has several questions about the existence and survival connected with the race taboo, whereas the second half gives answers to all the questions that appear in the former. The poem flows through a connection of poles of despair and hope. It is an amazing transformation of the poet's ideas that start building from despair but carry a lot of hope and energy. (Hope in the Dark, 2005) These ideas are autonomous parallel components.

The introduction of the rhythmic structure of the verses lays great emphasis on the idea that discrimination is deeply rooted in the society. Very beautifully he infuses couplets to make his point. These couplets 
have meter and the same rhythmic structure in the verse. The poet tries to create more of an impact through form and literary devices.

The poem begins with a very sad, distorted state of affair where the poet is wondering why does skin color matter so much when what matters more is the soul. He wants to know if it is the skin color that is a disgust or is it one's morals and values that matter. To him it seems as if the society hasn't been able to decide whether a person's attributes make him good or bad or is it his physical appearance that qualifies him to be a better person. The poet conveys the idea that this form of prejudice is based on appalling feelings towards others because of their gender, dogmas, societal status, religion, race, culture, dialect, race, or other personal characteristics. It is based on constructive or destructive valuation based on their perceived group affiliation (Dovidio, \& Gaertner. 2010). in where people are dealt with contrarily based on their social status attached to skin color. (Jones, 2001).

Alice Walker termed the word colorism in 1982. (Walker,1983). It is not in any sense a replacement for racism. Several aspects can donate to "race" (including ancestry); hence, ethnic classification does not exclusively depend on on skin color. Skin color is only one mechanism used to assign individuals to a racial category, but race is the set of beliefs and assumptions assigned to that category. Racism is the dependence of social status on the social meaning attached to race; colorism is the dependence of social status on skin color alone. In order for a form of discrimination to be considered colorism, differential treatment must not result from racial categorization, but from the social values associated with skin color. (Jones, 2001).

Extensive evidence has been researched related to discrimination based on skin color. In many countries lighter skin tones are preferable. (McIntyre, \& Simkovic, 2017)

The poet frustrated with the sticky labels and tags the society has designated him with just wishes to be accepted as a human being on this earth. He doesn't wish to be associated with any race, cast, creed, color, and he just wants freedom to live life. He wishes to exist and rise above all form to surpass and succeed in life. He wants to be upheld spiritually to wash away all impurities that the society associated with him. He wants to exist outside space and time where he is unknowable and unsearchable; in a way he desires an escape from the physical form and take flight in 
transcendence where he will be free from the worries of the world. Neither by an act of our will nor by our own reasoning can he get salvation from the conventional mindset. From a finite state he wants to transform into an infinite state. The human soul is galvanized. We all constitute the universe because when our soul departs for its eternal journey our soul becomes part of the echo system and our energy is transformed to the universe. The constant hammering of the negative color, has made him believe that to exist in this society he has to get it washed away, thus, he wishes to transform into godly characteristics because only God is divine and pure and the truly transcendent being. A desire has been infused in the poem to escape from the stickers that have been pierced into his skin and blood; it is like a seal that makes him believe that he is an outcast. So now it is no more a matter of the society giving him a tag, but he has accepted that he has to seek transformation to be clean. He wants to transcend and reappear in divine form in full revelation of God, when all things will be seen as they are, and mankind will treat each other better.

Ayana Dion, a correspondent and cultural critic is of the same opinion as Will Cox. She believes that the world will never value honor and sovereignty until the poor, uneducated and marginalized are treated with hatred are looked down upon just like we are treated by our oppressors. For as long as we have different scales to judge others and ourselves, we will remain buried under the weight of our failure and our invisible striving. The society makes humans feel contaminated. It treats them like filthy rags and like the autumn leaves that have no purpose. They wither and shrivel up and are swept with the wind. The society makes people believe they are a combination of everything sinful, impure, unclean or less than perfect; just to prove the society that it's only his skin that is pigmented but the color of blood running in the veins and the body functions with the same heart that pumps in every human. The poet wants to prove his righteousness and holiness and wants to clear the mindset and hearts of people through the indwelling spiritual power.

He refers to this hatred as a set of unfound beliefs (William J.) and it may include "any unreasonable attitude that is unusually resistant to rational influence". (Rosnow,(March 1972). Gordon McGraw refers to the poets ideas as a "feeling, favorable or unfavorable, towards a person or thing, prior to, or not based on, actual experience". (Allport, 1979). Auestad (2015), refers to Cox's work as a 'symbolic transfer', transfer of a value-laden meaning content into a socially formed category and then to 
individuals who are taken to belong to that category, resistance to change, and overgeneralization. (Auestad, 2015).

According to the poet his life and body both are in a frequency prison, (Perne, 2016). Where he is confined by force and authority is imposed on him and under law. He is denied to practice the rights and freedom that every individual has in a society. He feels both the mediums were created to enslave souls. Even when he is not guilty, he is made to accept that he is the culprit. He is seduced and manipulated until he accepts that he is the dark energy and the dark matter,- due to which the society is tainted. A similar but condescending idea has been used between the work of Will Cox and Wes Perne. Will Cox floats his desire as "I just wish to be...!", whereas Wes Perne's thought is expressed as "She just is!" - The disparity between these ideas is a human desire and a divine expression. The human desires survival irrespective of how he is maltreated and victimized, where as the "She" has been used for the "Divine Feminine or God" (Feng, 1998). Like God is present in everything and everywhere, God just is! Similarly, the battered human wishes just to be, holding on a strong desire of stepping on the next level of being divine. To skip this level (worldly stage) and jump on to the next level he wants to become heavenly where he will exist outside any universe and be a free soul. He wants to experience a variety of dimensions being in a hologram, beyond the physical universe.

Instead of bodily form he wants humanity to experience light as his form and become a divine existence. He wants to experience the power of love, security, reverence, divinity and pure harmony that the society has deprived them of, because of the hypothetical beliefs that we all look different. He looks forward to healing the world through the light of his soul.

Cox has very perceptively associated humans with the elements that fill the universe and are part of Mother Nature. The four elements fire, water, air and earth make the basis of many spiritual as well as magical systems. Each element possesses distinct characteristics; the poet makes a point by saying that the positive energy in the environment is due to these elements. These elements relate to metaphysics and philosophy and have practical application. (Wood, 1965) So much depth and insight has been infused in the words of the poet. He says that these elements emit vibes that influence the kind of life we live and also control the level of satisfaction and happiness we attain. He has seen himself in everybody and 
in this poem he's a persona of the entire human race. He says that he is part of the sun (fire) that is the strongest masculine element of all. Also considered as one half of the two symbolic polarities, yang. Having said, being the "...sun, relevant in all elements", Cox refers to the idea that sun is a source of heat, growth, warmth, light, and summer season. Most of all, life would be disconnected on the planet earth if the sun would not rise. Such is his importance to the world. Like the sun illuminates the entire universe, the poet too wants to enlighten the world by creating awareness for all those who are in the depths of the dark shadows following them. His world constitutes all those who are in anguish for their acts unknown. Time and again the poet jumps to the idea of re-living his life - a better life. Since he believes himself to be the sun, he believes he will never die because the sun is part of the Mother Nature.

Sun has a trait of burning. The sun consumes itself to enlighten the world; such are the poet's feelings for the entire human race. He is ready to consume himself to see the mankind grow. The sun too has characteristics like the yin and yang. It has a masculine feature (yang) and a feminine feature (yin). Just like the yin and yang maintain balance, similarly when the sun expresses its masculine energy it is symbolic to burning. However, when it expresses its feminine energy it is symbolic to a small flame, controlled, contained, yet helpful! The fire (sun) traits are love, passion, insight, leadership and generosity. The poet sees these traits diminishing from the world, and insists that he will always exist through the elements (Mother Nature) and his words will make him immortal.

Water is another most powerful element that can spread in any direction and flows free in its path. It is symbolic to a universal undertone of purity and fertility. It is viewed as a symbol of life itself. Indications in countless mythologies have been witnessed life has emerged from water. (David, Barnes \& Noble, 2016), Water can dissolve the hardest mountains. It represents strength, freedom, life and creativity. The poet expresses his desire to be immortal and says that just like the sediments lie on the bed of the ocean and sit there for long years, in the same way his remains will always be part of the earth and he will continue to exist like the sediments that are broken down with erosion and are carried from one place to another either by wind or water or by the force of gravity transporting the minute particles. Research claims that the bottom of the ocean is extremely cold, resulting in preservation of the sediments in the depths. (Jessica, Dermot, Scott, \& Warwick, 2008) Through erosion the small particles rest on the bed of the ocean but the larger ones are transported all around the 
globe until they break down to the minutest size, therefore the poet is assuming different forms to be present in time and heal the world with his divine presence.

The poet is ambitious for humanity to achieve serenity and inner peace by reaching its highest and the deepest continuum. Taking flight into the sky symbolizes his high aspirations that have no limits as he wants to surmount Mount Everest which is the highest peak and is still growing. It grows about half an inch each year as they are pushed up by the collision between the Indian and the Asian land masses. Cox wants to maintain a balance in this journey of life by hitting the highest and the lowest points. Life has been explained as a never ending journey because the soul is eternal. Taking flight into the sky is also symbolic to elevation of the soul to the next level. The journey of the soul is an evolving process. As the journey undergoes transformation and proceeds from one level to another level, it keeps growing consciousness and rediscovers the inner self. It would be a huge step forward for humanity to beam back and reveal that very soon the world will offer the right conditions of survival for life no matter who inhabits it. The world is at the verge of witnessing a radical transformation based on the capability that whatever we set our minds to, we can achieve it. The poet anticipates ascending to higher things like the celestial railroad (Nathaniel, 2015), where inner peace is preserved. He sees the world trapped in an eclipse and is looking forward to spread the same peace message that the universe holds in its bosom. Johannes Kepler, a mathematician, astrologer and astronomer of the 17 century, well known for his contribution towards the laws of planetary motion and universal gravitation, was of the opinion that God created mankind with the idea that man could discover the true essence of the universe as he remains connected being a part of the universe. (B. Y., L. 1996). Like the universe has been organized harmonically, the poet tries to discover the existence of love and harmony that the universe holds in its bosom. He foresees the universe to yield a more accurate representation which in every sense is more desirable and irresistible. It reveals how the world offers the right conditions for life by offering peace and harmony. The harmony that runs our solar system is the same harmony that is expected between humans but the order between humans seems disrupted because we have not been able to maintain a balance in our lives.

The idea of creating harmony in the world order has amazingly been picked up by many writers. Like Will Cox, even J. Kepler in his book "The Harmony of the World" presents his views that the world was 
organized harmonically, and he has discussed the connection of harmony between the man and universe. He defined man as the universe as he has proved in his work that like the diverging and converging celestial objects, man also functions similarly. (Johannes . Barnes \& Noble, 1997) The solar system as well as the human body is an interactive dynamic system that operates around spreading peace in the environment.

The question is that humans are made up of skin, flesh and bones whereas the universe constitutes the stars, galaxy, solar system and other illuminating forces, so how can the two physically different systems connect? To simplify, we all are made up of the same elements that make up the universe. The atoms that make our bodies are found floating in the universe that also form stars in the galaxy. It is however difficult to compare humans with the entirety of the infinite galaxies the universe holds in itself which seems impossible to conceptualize, though it is true that humans are made up of stardust (the same matter).

It's our perception that creates reality and every one of us has a distinct perception due to which we all have a different realities. Even though we all live in the same physical universe, yet we all have our own universe within ourselves which is our perception and reality. This perception and reality collides and overlaps with others that brings about the imbalance, yet, at times it also matches with someone. The concept of spiritual energy is as ancient as humanity.

The soul is the essence and the active consciousness that flows through life. Everything in the universe, whether the humans or the galaxy is an expression of energy. It includes our thoughts and feelings and the active, passive or aggressive motion of the stars and planets. Since both are different entities, they have different ways of expression yet they are the same. Energy is guided by our soul that produces waves that influence occurrences in life, time and reality. The placebo effect lies in how thoughts escort the manifestation of reality. When the energy flows for the right cause, it results in free movement but when it flows for a chronic issue, it gets disrupted and disturbed. This is what we witness between humans and the same stress is found in the galaxy in the movement of the stars when there is an imbalance in the smooth flow of energy that sustains life. The human bodies have an electromagnetic field around their bodies that reflect the force of energy that controls our life. The poet wishes to expand his intuitive vision to perceive the radiant energy that guides the 
humans to rebalance the energy that is provided by the soul as a spiritual essence to flow in a more harmonious way.

Cox wants to live life through a soul perspective which is enlightenment and living life supported by a deep sense of inner knowing and connection. On the contrary the thing that humans are missing out is the connection of the self with the soul. We fail to connect with the wisdom that our soul tries to transfer in us. If we would listen to the quiet whispers of our soul we could make this world a better place because every soul is pure, and free from the chaos that exists in the physical world. Our souls work at peace. Everything in the outer universe is a reflection of our consciousness and our soul. Our body is made up of the same elements and energy as the planets. Just so to mention a minute fact that the percentage of water on the plant is the same percentage of water that our bodies are made up of. The celestial bodies are similar to the humans in several respects. They are both alive, just that the celestial bodies are soundless, whereas the human beings are vocal! The difference only lies in expression that has more or less the same effects and results. The poet tries to establish the point that even though we are nature-beings (Chuck, 2002), we have fallen out of alignment because wellness is associated as being in tune with nature. Knowing the fact that spending time being close to nature dramatically improves and makes our lives better. Nature is not just the outside world but it exists within us. For example we are made up of the same water the planet is made up of, the heat and fire that keeps us warm is the same fire that burns the sun, the vitamins, minerals and calcium that make our bones are the same elements that come from nature, also the oxygen that we need to keep us alive has a reciprocal relationship with the plants and trees as it keeps both of them alive and is also part of what builds the cosmos. The moon that controls the high tides and low tides and the waves in the sea, also significantly controls our emotions or the inner waters, (Michelle) so not only the external universe (the physical universe) but also the internal universe (human mind and body) is greatly affected by the waxing and waning of the moon. Hence, all these elements or Mother Nature is feeding and nurturing us, therefore we become a part of this dynamic system. We all hold in us the force that orchestrates to form the entire universe as we all are directly or indirectly connected with each other. By connecting with our soul we directly get connected with the universal soul that controls the entire cosmos. We remain unaware that we are connected to an expansive range than an obstructive range. Our sense of intuition starts connecting with reality and expands our horizon making our lives better. 
We are created from Earth and at the end of the incarnation journey we return our bodies to Mother Earth being made up of the same components whereas our soul transfers to the next level to connect with the physical universe- stars and galaxy. Many ancient civilizations sought guidance and energy from stars because when we return to Mother Earth, our soul goes back home to the stars. Having being made up of stardust, these celestial bodies connect with ours through waves and take us beyond the supreme consciousness. The beauty of the soul is that it connects and collaborates with the external energy and paves the way with the quantum mind to become one with the universe. The soul attains spiritual enlightenment when the mind is free from the worldly chaos and is more closely connected with the universe. Because of the cosmic energy between the elements and the human body, we start feeling that we are more alike than different. It is mainly because the universal connection with the divine soul melts all restrictions and creates love and harmony everywhere. To accelerate in our spiritual journey all we need is a peaceful mind and a loving heart that makes the soul grow fonder.

There are harmonic proportions in the solar system that correspond to the working of humans. Both the physical bodies work with in the harmony in their own orbits.

The key lies in being able to identify oneself through the energy vibes emitted by the elements, being conscious of what and who we are and accordingly attune ourselves to get the best out of such waves for a fuller existence. In order to attain consciousness from the surrounding one has to be in touch with the inner self, listen to the heart, mind and body. All one has to do is to sense, feel and alter it according to the need of the environment. The universe emits vibes that influence us only if the environment is kept clutter-free. The human soul is like an intriguing maze, we are unaware how much power and strength it holds in itself because it can alter the course of life. We are all trying to rush through time whereas the universe is timeless. We should pay respect through our actions and behavior and make others feel included rather than excluded. Labels enable a person to construct a powerful tool to use as their identity. This widespread disenfranchisement should be condemned. Ego is a race that sets bondage and categorizes people and the winner in this race is a loser. We are all so caught up in time that we forget our real identity and the goodness associated with our souls and keep building strong connections with things that are appealingly attractive but base. 
People are always looking forward to worldly gains and pleasures, they are running after materialistic things which puts them in the dark and dissolute bottomless pits, overlooking that they should stop bickering about racial injustices and pave way for a rock solid brotherhood because having scorched in the infernos of withering prejudice, no color will have victory. It is just a sprint that everyone unknowingly participates in and no one wins. Cox compares this running race to a hamster running on the wheels, it keeps running purposelessly in circles and reaches nowhere, similarly humans are also making the same mistakes in life repeatedly, instead of progressing or changing their course of life. There will be no rest and tranquility until the physical differences are eliminated that give rise to bitterness and hatred. It's not the human color that matters; rather, it's the human soul that is significant. Life is above all prejudice; it's the concept of spirituality that only good people achieve.

We are an outward expression of the creator. How great are His miracles and how mighty His wonders! We are just a minute expression of his inward thought. Humans are the most evolved of all creations on earth. God created us to glorify him; (Kathy, Midge, Ronald) instead we are negating the importance of the body in true spirituality. (Kathy, Midge, Ronald) Instead of loving god for making us the supreme beings, we have fallen in love with worldly things with all our heart, soul, mind and strength.

Cox uses sand as a metaphor for life to explain that each one of us is different and have led different lives and experiences. Like two snowflakes are not the same, similarly people are not the same. Our life is constant but our soul is in constant rhythm of transition. It comes from heaven, transferred to this world in body form and after the body falls, the soul escapes from the dimensions of density and form and once again leaves for its journey and remains in constant transition. Death is not the end; it's the beginning of a spiritual journey. It goes through a life changing transition of enlightened consciousness. In many cultures and religions the process of death and dying is considered a powerful opportunity for spiritual liberation. (Baeu, Wu ,\& Yeager, 2007),

Towards the end the poet personifies himself and we hear him leaving a message for the entire human race. The poet expresses his views that we are not just common people but we are made up of unique traits. He draws connection with the star seeds, crystals and Indigos. These names were given to generations incarnated/born in different times as they 
accurately portrayed their aura, emblems and energy patterns. These are universal concepts that reflect new generations between certain time phases. People witnessing the process of a spiritual awakening are usually described as one of the above terms. Our souls experience simultaneous realities, timelines and multiple dimensions all the time referred to as labels. Any human is capable of going through the point of evolving their consciousness.

These names are nothing more than different aura colors and various personalities; we are all part of the universe because we are created from stardust. The Universe is inside us. It is important to see that while there may be various personalities between them, these labels do not matter deep down. Everyone on this Earth has the potential to understand their own divinity because we are all connected as one.

Even if you are indigo, crystal or the star seeds, it doesn't make you more or less important because when you resonant with the rest, the undercurrent is the same, we are all going through the process of Spiritual Awakening. Cox's message to the world is not to get hung up with the labels, the divinity within him, honors and respects the divinity within the entire humanity, we are one!

The star-seeds are highly intelligent, extremely creative and intuitive with a strong sixth sense and have great affinity with the cosmos. They are drifted towards the spiritual journey that leads to spiritual awakening. The Crystals were born in 1980-2010 and the influx was around 2000. They are very gentle souls who have opalescent with multicolored pastel hues in their auras. They have incarnated to help us to connect back to our original source and to bring peace and harmony. The crystal children have incredible telepathic abilities and are wise beyond their years. They are philosophically and spiritually gifted and are amongst the most connected, communicative, kind and caring. The children that fall into this category care for everyone in need. The Indigos were born around 1925 but the influx came in around 1970 through to 80's. They have indigo auras hence the name! They are here on this planet to break the molds, to bring down the old ways, also known as the generation $\mathrm{X}$. They have psychic powers and warrior energy. They have hot temper and fiery determination and are mostly clairvoyant. After the World War II, a lot of indigo children were born who are the Indigo adults today, who are helping to change the world. 
Talib Kweli in his "From Ferguson to Freedom: Hip Hop's Role" encourages artists to use their platforms to spark change and he further adds to the same idea of the universal concept of the generations by adding that the old way of doing things is being challenged by new generations. (Kenrya, 2015)

The poet wants to heal the world and personifies himself as Indigo with healing abilities. He wants to ignite a flame to eliminate the darkness that has overshadowed the hearts of people. He knows that he is here for a purpose and he will be a blessing to humanity. With his warrior like presence he intimidates those who put others on trial and turbulence. He is a born activist. Like King Martin Luther and Mother Teresa, Will Cox wants to remove all suffering and inequality from the world and spread the message of peace and love. He is light and love and has a pure soul. He refuses to tolerate injustice. He is the Spiritual Indigo Warrior! He believes in winning the hearts of people with love and compassion and defines these emotions as non-materialistic. One cannot get them in exchange of money or value. They can't be bought but only can be bought if we all feed the souls of our brothers with love and compassion. Love is the language of the soul. His last words before he concludes the poem are that after all the emphasis on how color, caste, creed and race builds a divide between us, if people still continue to tag and label others, then he takes an aggressive stance to let them know that he is an Indigo Warrior for them to shun their conservative beliefs and dogmas who are purposely running with time to gain materialistic fame. 


\section{REFERENCES}

Allport, G. (1979). The Nature of Prejudice.Perseus Books Publishing.p. 6.

ISBN $\underline{0-201-00179-9}$.

Auestad, L. (2015). Respect, Plurality, and Prejudice (1 ed.). London: Karnac. pp. xxi-xxii.ISBN 9781782201397.

Bedrich V. H. (2008), The Reality of God in the Universe, Bloomington, IN , Brian W.R.,(2001), The Guardian's journalist,Oxford University PressB. Y., L. (1996). The Unfinished Universe.Oxford University Press. Barnes and Noble,

Cambridge Dictionaries Online.(2013)Cambridge University.Retrieved 29 March.

Chuck C., (2002), Concepts of Fitness and Wellness, Arizona State University, USA Baeu S. Wu ,R. B.,\& Yeager, K.. (2007), Vol 13,Issue 2, Spritual Perspectives \& Practices at the end-of-life, , Nell Hodgson Woodruff School of Nursing, Emory, University Atlanta, GA, USA.

Dovidio, J. F., \&Gaertner. S. L. (2010). "Intergroup bias". In S. T. Fiske, D. T. Gilbert, \& G. Lindzey (Eds.), The Handbook of Social Psychology (5th ed., Vol. 2). New York: Wiley.

David W., Barnes \& Noble, (2016), NY, The Ascension Mysteries, Feng S. (1998) Journal, The Five Toaist Elements. Spring Vol 4,No 1,. pgs 22-25

Hernandez LM, Blazer DG, (2006) Editors , Genes, Behavior, and the Social Environment: Moving Beyond the Nature/Nurture Debate. Washington (DC): National Academies Press (US);

Hope in the Dark, (2005) Rebecca Solnit, Canongate, Introduction to sociology. (2009) 7th ed. New York: W. W. Norton \& CompanyInc,.p. 334.

Jones, T. (2001). "Shades of Brown: The Law of Skin Color". Duke Law Journal. 49 (1487).doi: 10.2139/ssrn.233850.

Johannes K., .Barnes and Noble (1997) ,, The Harmony of the World, United States

Jones, T (2001). "Shades of Brown: The Law of Skin Color". Duke Law Journal. 49 (1487). doi: $10.2139 / \mathrm{ssrn} .233850$. 
Jessica D. T. , Dermot A., · Scott F. L., · Warwick F V., (2008) Journal of Paleolimnology, Queen University, Ontario

Judith F.,(1995) Race to Justice: A Racial Justice and Diversity Program for Junior High, Robin F. Gray, José A. Ballester y Marquez, , Universal Association, Boston,

Kenrya R. (2015)Colorlinespublished by Race Forwards,JUN 30, 10:52AM EDT (NEWSPAPER REFERENCE)

Kathy R., Midge W., Ronald E. H., The Color Complex: The Politics of Skin Color Among African Americans,

Michelle F., The Wheel of the Healing Ayurveda

McIntyre, F. \&Simkovic, M. (2017)."Are law degrees as valuable to minorities?".

International Review of Law \& Economics.doi:10.1016/j.irle.2017.09.004.

William J. wrote: "A great many people think they are thinking when they are merely rearranging their prejudices." Quotable Quotes - Courtesy of The Freeman Institute

Nathaniel H., (2015), The Perfect Library, The Celestial Railroad, NY

Perne, W.. (2016). "Synthetic Super Intelligence and the Transformation of Humankind"

Rosnow, R. L. (March 1972). "Poultry and Prejudice".Psychologist Today.5 (10): 53-6.

Sharmila R., (2013) Alter Your Reality:Re-Establishing the Divine Connection, Penguin Books, New Delhi,

Walker, A. (1983). "If the Present Looks Like the Past, What Does the Future Look

Like?" (1982)". In Search of Our Mothers' Gardens. 290: 290-91.

Wood, C. A. (1965) "Teaching Hawthorne's "The Celestial Railroad." The English Journal 54.7: 601-605: 601 . 